
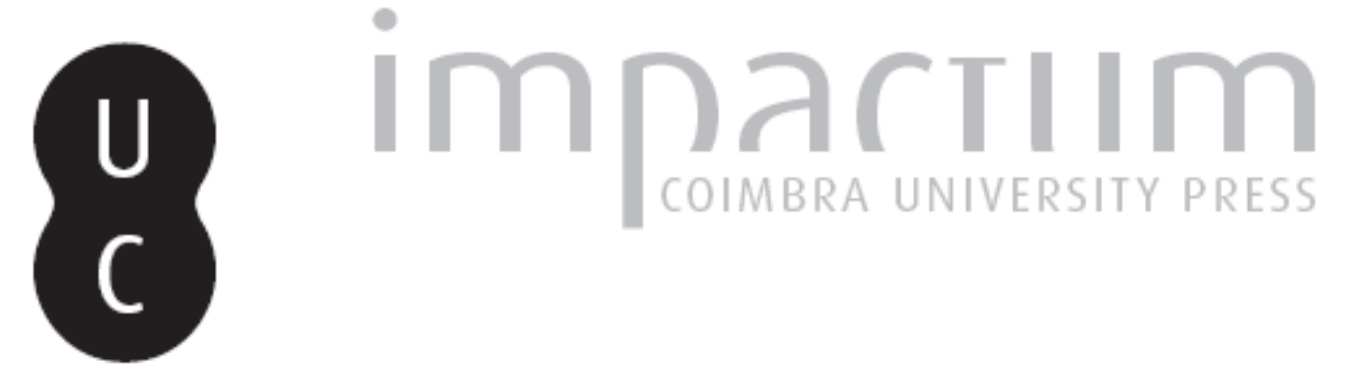

\title{
Os locais de interesse geológico do Cabo Mondego: proposta de recuperação das pedreiras tendo em atenção os riscos geomorfologicos identificados
}

Autor(es): Rocha, João Nuno Correia

Publicado por: Associação Portuguesa de Riscos, Prevenção e Segurança

URL persistente:

URI:http://hdl.handle.net/10316.2/36198

DOI:

DOI:http://dx.doi.org/10.14195/1647-7723_15_6

Accessed : $\quad$ 26-Apr-2023 03:00:51

A navegação consulta e descarregamento dos títulos inseridos nas Bibliotecas Digitais UC Digitalis, UC Pombalina e UC Impactum, pressupõem a aceitação plena e sem reservas dos Termos e Condições de Uso destas Bibliotecas Digitais, disponíveis em https://digitalis.uc.pt/pt-pt/termos.

Conforme exposto nos referidos Termos e Condições de Uso, o descarregamento de títulos de acesso restrito requer uma licença válida de autorização devendo o utilizador aceder ao(s) documento(s) a partir de um endereço de IP da instituição detentora da supramencionada licença.

Ao utilizador é apenas permitido o descarregamento para uso pessoal, pelo que o emprego do(s) título(s) descarregado(s) para outro fim, designadamente comercial, carece de autorização do respetivo autor ou editor da obra.

Na medida em que todas as obras da UC Digitalis se encontram protegidas pelo Código do Direito de Autor e Direitos Conexos e demais legislação aplicável, toda a cópia, parcial ou total, deste documento, nos casos em que é legalmente admitida, deverá conter ou fazer-se acompanhar por este aviso.

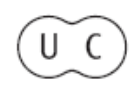




\section{territorium}

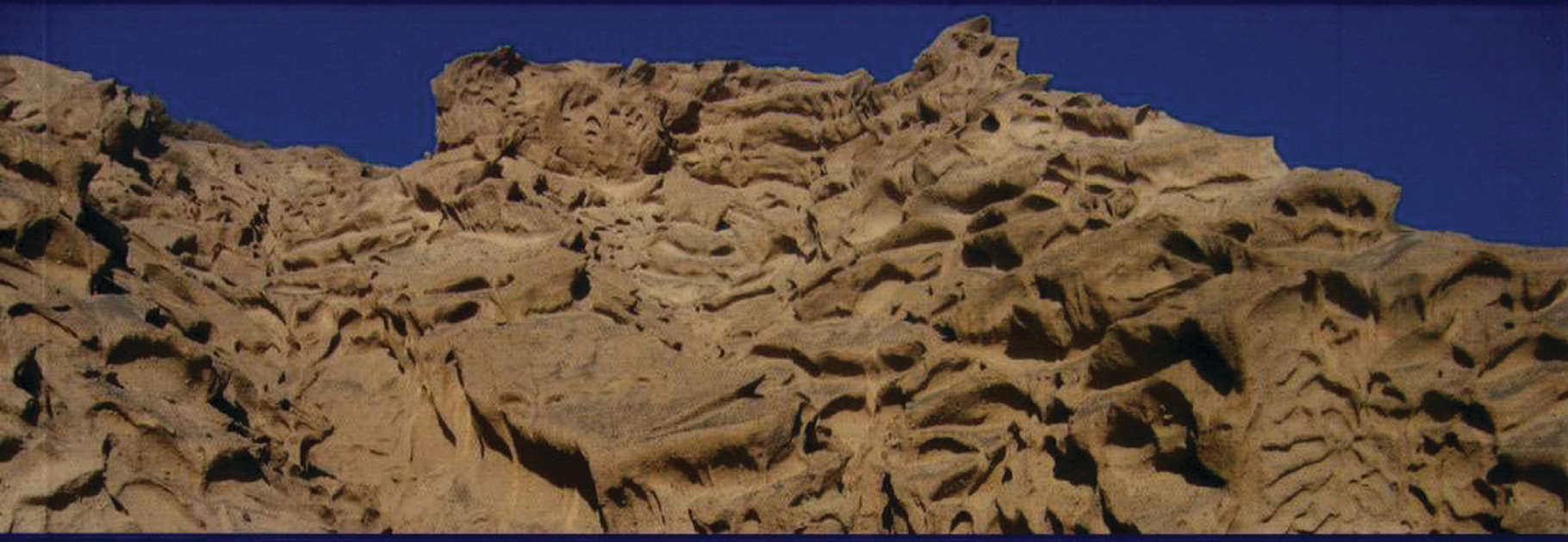

15

Revista da Associação Portuguesa de Riscos, Prevenção e Segurança 2008 


\title{
OS LOCAIS DE INTERESSE GEOLÓGICO DO CABO MONDEGO. PROPOSTA DE RECUPERAÇÃO DAS PEDREIRAS TENDO EM ATENÇÃO OS RISCOS GEOMORFOLÓGICOS IDENTIFICADOS*.
}

\author{
João Nuno Correia Rocha \\ joaorocha@nicif.pt \\ Geógrafo. Núcleo de Investigação de Incêndios Florestais - FLUC \\ e Centro de Geociências - FCTUC
}

\begin{abstract}
RESUMO
Na Serra da Boa Viagem - Figueira da Foz - está implantada uma indústria extractiva cuja actividade tem contribuído para a destruição de parte do seu sector ocidental - o Cabo Mondego. Os profundos impactes decorrentes da extracção do calcário são visíveis ao longo das vertentes adjacentes ao Monumento Natural do Cabo Mondego, contribuindo para a desvalorização desta Área Protegida e comprometendo o seu usufruto público.

O presente trabalho tem como objectivo principal propor algumas estratégias que possibilitem a reconversão, recuperação e revitalização das áreas de pedreira, conferindo-lhe novas funções e valorizando as suas potencialidades. Pretende-se, de igual modo, potenciar os valores patrimoniais reconhecidos - geológico, biológico e arqueológico industrial -, projectar cenários que permitam o desenvolvimento de actividades científicas, turísticas e lúdicas e desenvolver estratégias de valorização e protecção daquele Património Natural.
\end{abstract}

Palavras chave: Cabo Mondego, Monumento Natural, locais de interesse geológico, reconversão de pedreiras, património natural, riscos de movimentações em massa.

\begin{abstract}
In the Serra da Boa Viagem - Figueira da Foz - there is an established industry whose business has contributed to the destruction of part of its western sector - the Cape Mondego. The profound impacts arising are visible along the sides adjacent to the Natural Monument of Cape Mondego, contributing to the devaluation of this Protected Area and undermining its public enjoyment.

This work aims mainly to propose some strategies that enable conversion, recovery and revitalization of the quarry, assigning it new functions and evaluating its potential. It also intends to enhance recognized values - geological, biological and archaeological industry - in order to design scenarios that enable the development of scientific activities, tourism and leisure, and develop strategies for recovery and protection of that natural heritage.
\end{abstract}

Key words: Cape Mondego, Natural Monument, places of geological interest, quarries conversion, natural heritage, mass movements hazards

\section{RESUMÉ}

Dans la Serra da Boa Viagem - Figueira da Foz - l'activité extractive de plusieurs carrières a contribué à la destruction d'une partie de son secteur ovest - le cap Mondego. Les profondes incidences sont visibles sur les côtés adjacents au Monument Naturel du cap Mondego, ce qui contribue à la dévaluation de cette aire protégée et sape son utilisation publique.

Le but de ce travail c'est proposer des stratégies qui permettent la conversion, la récupération et la revitalisation des zones de carrière, en lui donnant de nouvelles fonctions et incrémenter son potentiel. On veut, également, renforcer les valeurs patrimoniales reconnues - géologiques, biologiques et archéologiques industriels -, concevoir des scénarios qui permettent le développement des activités scientifiques, du tourisme et de loisirs, et élaborer des stratégies pour la valorisation et la protection de ce patrimoine naturel.

Mots clé: Cap Mondego, Monument Naturel, lieux d'intérêt géologique, conversion de carrières, patrimoine naturel, risques des mouvements en masse

* Comunicação apresentada ao IV Encontro Nacional de Riscos, Coimbra, 10 de Março de 2008. 


\section{Introdução}

O Cabo Mondego localiza-se no bordo ocidental da Serra da Boa Viagem (latitude $40^{\circ} 11^{\prime} 3^{\prime \prime} \mathrm{N}$, longitude de $08^{\circ} 54^{\prime} 34^{\prime \prime}(\mathrm{W})$ aproximadamente 5 $\mathrm{km}$ a Noroeste da Figueira da Foz (fig. 1).

Do ponto de vista morfológico, a Serra da Boa Viagem é um pequeno maciço de rochas sedimentares que se destaca da costa plana de toda a região. Este apresenta uma forma assimétrica, sofrendo um estreitamento de Oeste para Este, sendo de realçar o carácter abrupto das vertentes Norte llimitada pela fallha de Quiaios) e Oeste, onde podem ser observadas algumas arribas, contrastando com as vertentes mais suaves voltadas para Sul (PINTO, 1997).

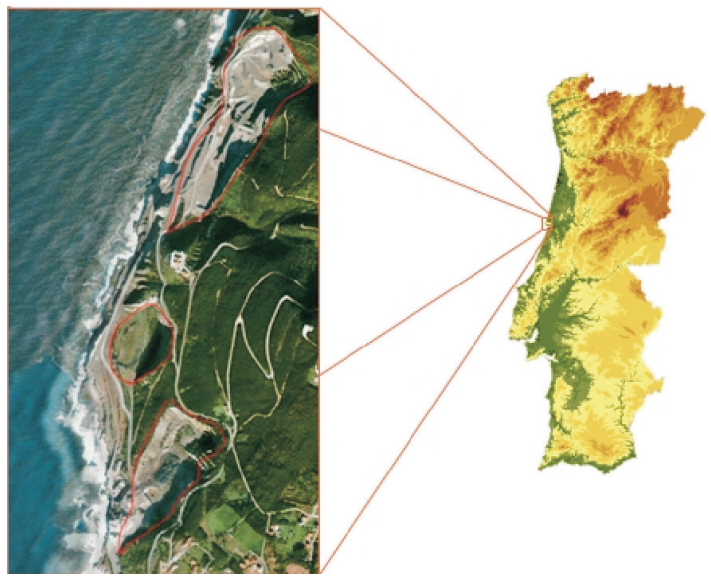

Fig. 1. Localização da área abrangida pelo presente estudo.

Inserido na Bacia Lusitaniana, o Cabo Mondego é constituído, grosso modo, por materiais mesocenozóicos, com rochas carbonatas, margosas e calco-margosas jurássicas e cretácicas (MOUTERDE, et $a l, 1978)$. No seio dos materiais jurássicos, afloram as formações designadas Complexo Carbonoso e Calcários Hidráulicos, as quais constituíram motivo de interesse económico e estão na origem da actividade extractiva.

A actividade mineira no Cabo Mondego teve início em 1773, com a extracção de carvão mineral na Mina de Carvão de Pedra de Buarcos, reconhecida como uma das mais antigas explorações carboníferas em Portugal (MENDES, 1998).

No início do século XIX, é construído o primeiro forno de cal, iniciando a transformação do Couto Mineiro (complexo industrial onde se explorava o jazigo carboníferol em Complexo Industrial do Cabo Mondego, com a instalação das indústrias de Cal, Cerâmica, Vidro, Electricidade e Cimento (MENDES, 1998; SOlla, 1970; SANTOS, 1982).
A exploração de matéria-prima destinada ao fabrico de cal hidráulica desenvolveu-se numa área de aproximadamente 58 hectares. Esta é constituída por três pedreiras (limitadas a vermelho na fig. 1), as quais são designadas por pedreira norte (A), centro (B) e sul (C) (fig. 2) com base nas suas posições geográficas relativas. As pedreiras sul e centro já estão desactivadas, enquanto a pedreira norte está actualmente em fase de exploração.

De toda a actividade extractiva realizada no Cabo Mondego resultaram impactes ambientais que são bem visíveis na paisagem (fig. 2), com riscos de desabamento em grande parte da sua extensão. Todo este espaço, afecto à actividade mineira, deve ser objecto de um plano de recuperação e de reconversão, no sentido de minimizar tais impactes e riscos, nomeadamente através do estabelecimento de novas funções e dinâmicas às áreas de pedreira sem, no entanto, descuidar a valorização e preservação dos diversos valores (natural e histórico) ali reconhecidos.

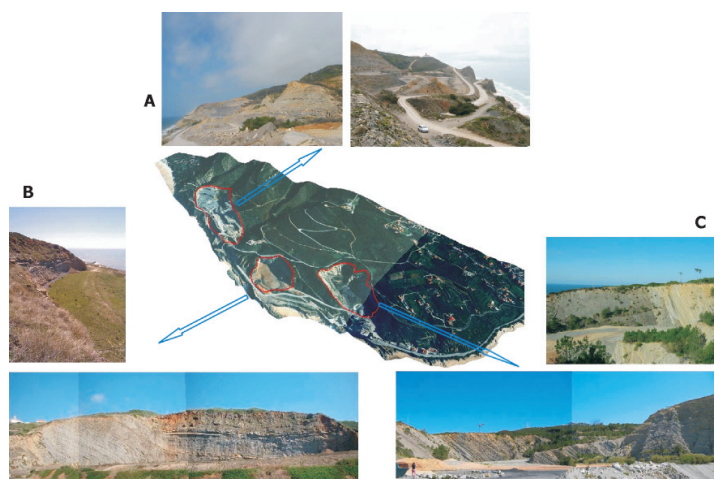

Fig. 2. Localização das pedreiras norte (A), centro (B) e sul (C) no Cabo Mondego.

\section{Património Natural: conceitos e instrumentos legais para a sua preservação}

As referências ao património natural de determinada área consagram, normalmente, diversas descrições relacionadas com os aspectos faunísticos e florísticos e, por vezes, aspectos paisagísticos. Contudo, a definição adequada de património natural deve integrar as duas dimensões (geológica/ geomorfológica e biológica) que sustentam o património de um dado território ou local (BRILHA, 2005).

O património natural, em termos de instrumentos legislativos que o "protejam", não tem obedecido àquele entendimento, verificando-se uma clara diferença entre os pesos atribuídos pelo legislador ao património biológico relativamente ao geológico. 
Os valores predominantemente biológicos, que servem de base à classificação de áreas protegidas actualmente existentes, dominam claramente sobre os interesses predominantemente geológicos. Assim, o número de áreas classificadas por razões biológicas $(43 \%)$ é muito superior face ao número de áreas classificadas por razões geológicas (23\%), apesar deste ser considerado como uma componente fundamental e indissociável do Património Natural (Oliveira \& Henriques, 2000).

A legislação que actualmente regula o Património Natural português (Decreto-Lei n. ${ }^{\circ}$ 142/2008 de 24 de Julhol tende a dar mais relevo ao Património Geológico, completamente ignorado na anterior (Decreto-lei nㅇ19/93, de 23 de Janeiro), e consagraIhe especificamente a figura de Monumento Natural, a que corresponde:

\section{"Artigo 20.}

Monumento natural

1 - Entende-se por monumento natural uma ocorrência natural contendo um ou mais aspectos que, pela sua singularidade, raridade ou representatividade em termos ecológicos, estéticos, científicos e culturais, exigem a sua conservação e a manutenção da sua integridade.

2 - A classificação de um monumento natural visa a protecção dos valores naturais, nomeadamente ocorrências notáveis do património geológico, na integridade das suas características e nas zonas imediatamente circundantes..."

\subsection{O valor biológico do Cabo Mondego}

Tratando-se de uma área de extrema sensibilidade ecológica e ambiental, a Serra da Boa Viagem está actualmente protegida por uma série de instrumentos e servidões/restrições designadamente a Rede Natura 2000 (rede ecológica resultante da implementação da Directiva Fauna, Flora e Habitats), e Biótopos Corine.

\subsection{O valor geológico/geomorfológico do Cabo Mondego}

No decorrer do século XX, vários foram os investigadores que se debruçaram sobre a geologia do Cabo Mondego e que relevaram o valor do registo geológico ali aflorante, designadamente através das descrições dos registos paleontológicos de peixes (VIANNA, 1949; GONÇALVES, 1959), de icnofósseis de dinossauros (LAPPARENT, 1951) e, de forma mais exaustiva, de amonóides, distribuídos ao longo de uma espessa série sedimentar que representa " (...) um importante período da história da Terra - o Jurássico" (HENRIQUES, 1998, p.2).

No Cabo Mondego, o Jurássico está representado por uma série sedimentar contínua de sedimentos marinhos e flúvio-lacustres, datados do Toarciano superior ao Caloviano médio, entre 185 e 140 milhões de anos (Henriques, 1998; CallaPez, et al, 2006). O Jurássico médio é caracterizado pela ocorrência de fácies marinhas, com abundante registo paleontológico de amonóides, que permitem datar com uma precisão notável as idades dos materiais aflorantes (Henriques, 1994; HeNRIQUes, 1998; FERNÁNDEZ LóPEZ et al., 2008).

Este registo estratigráfico é de tal forma importante nomeadamente porque inclui associações de amonóides diversas, abundantes e com estado de conservação adequado - que, em 1994, o perfil da passagem Aaleniano-Bajociano ( 176 a 179 milhões de anos), situado na Murtinheira, foi proposto como estratotipo do Bajociano, tendo sido considerado, dois anos depois (PAVIA \& ENAY, 1997), como o melhor afloramento, a nível internacional, para o estabelecimento do Global Boundary Stratotype Section and Point (GSSP) daquele andar. Trabalhos de paleontologia de outros grupos fósseis braquiópodes (ANDRADE, 2004) e foraminíferos (CANAles \& Henriques, 2008) - realizados posteriormente, têm vindo a reforçar o valor estratigráfico ímpar então reconhecido.

\subsubsection{O Monumento Natural do Cabo Mondego}

O património geológico do Cabo Mondego reúne um conjunto notável de elementos que devem ser considerados em figuras legais com o objectivo de desenvolver estratégias de Geoconservação.

As figuras de Paisagem Protegida e de Monumento Natural, definidas nos art. 8e 9을 do decreto-lei n19/93, permitiam estabelecer possíveis estratégias relativas à protecção do património geológico do Cabo Mondego, que culminaram, em 1994, na sequência de Presidência Aberta sobre o Ambiente do Dr. Mário Soares, com a elaboração de um Relatório de Fundamentação Científica de apoio a uma proposta de classificação do Cabo Mondego como Monumento Natural.

A importância patrimonial do Cabo Mondego, assim como o seu valor geológico ambiental e paisagístico, 
são argumentos que estiveram na base da aprovação da proposta de classificação deste local como Imóvel de Interesse Municipal, em Abril de 2003, pela Assembleia Municipal da Figueira da Foz.

Finalmente, a 3 de Outubro de 2007, é publicado em Diário da República o Decreto Regulamentar nำ/ 2007, no qual é atribuído o estatuto de Monumento Natural para o Cabo Mondego, com base na riqueza paleontológica, nas condições de observação, na continuidade do registo e no valor científicopedagógico deste local, reconhecido nacional e internacionalmente. (fig. 3).

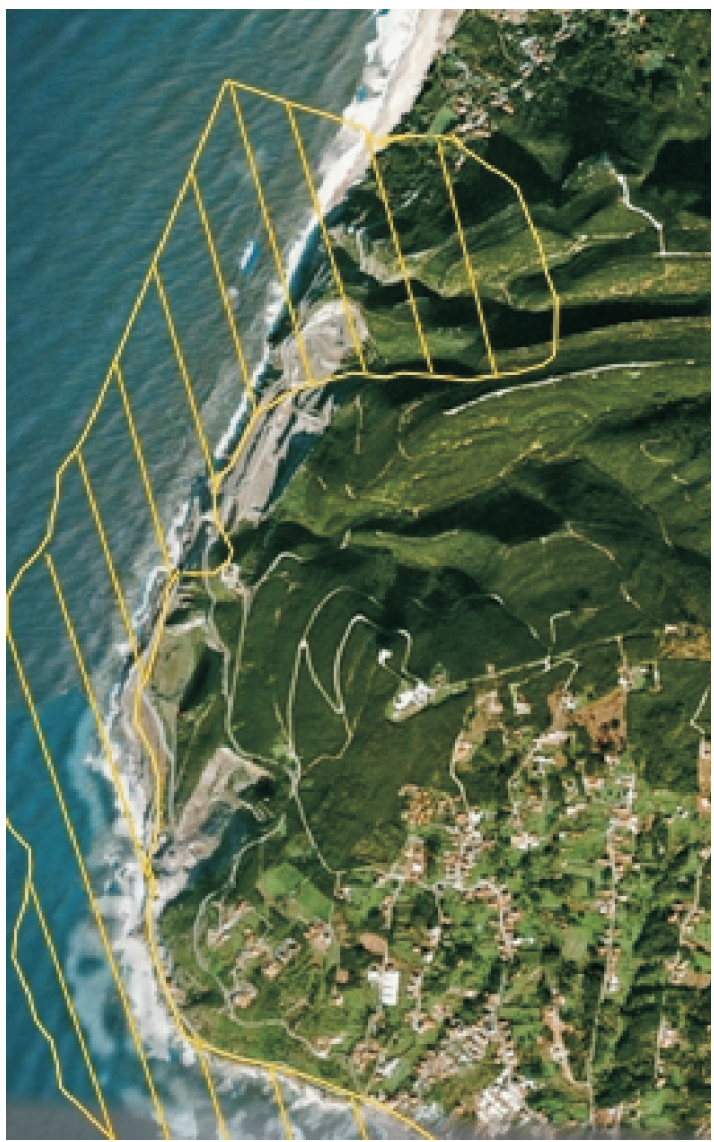

Fig. 3. Limite de Protecção do Monumento Natural do Cabo Mondego.

\section{O Projecto de Reconversão do Cabo Mondego}

A actividade mineira instalada na Serra da Boa Viagem é responsável pela destruição da topografia original e pelos profundos impactes visuais, marcados pela presença de três grandes pedreiras, onde os riscos de desabamento são elevados.

O presente trabalho propõe algumas medidas de reconversão paisagística e funcional deste espaço, fazendo uso dos diversos valores existentes, os quais devem ser objecto de um processo de valorização capaz de definir estratégias de conservação, valorização e divulgação, integradas numa perspectiva de desenvolvimento sustentável.

A atribuição do estatuto de Monumento Natural ao Cabo Mondego deu o enquadramento legislativo a esta área que garante a sua integridade física, o que permite que ali se possam desenvolver e implementar as acções de conservação, designadamente a valorização dos diversos locais de interesse. Este último aspecto deve permitir a definição de níveis de qualidade e de importância do património, bem como contemplar um conjunto de acções de informação e de interpretação, que permitam ao público reconhecer o valor deste local de interesse geológico (BrLLHA, 2005).

\subsection{A Pedreira Sul}

Esta pedreira, actualmente desactivada, está instalada nas proximidades das instalações da fábrica onde se desenvolve o processo fabril de produção de cal hidráulica (fig. 4). Neste sector, podem ser reconhecidos alguns vestígios de uma das mais antigas explorações carboníferas de Portugal, cuja

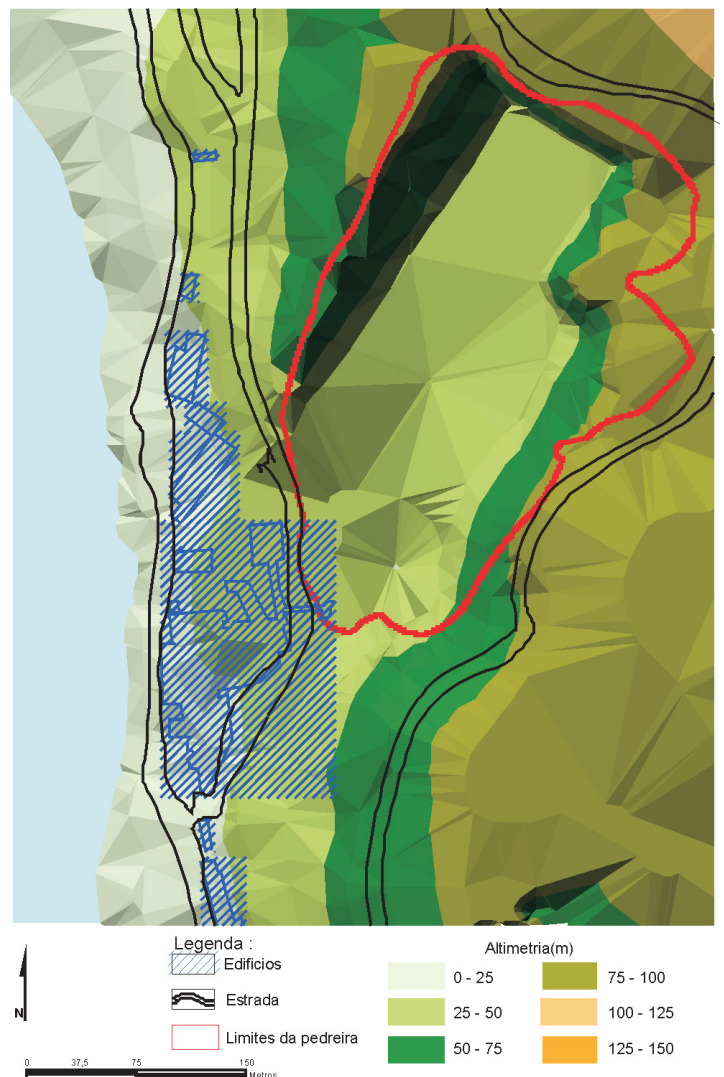

Fig. 4. Delimitação da Pedreira Sul e localização dos edifícios adjacentes. 
actividade se iniciou em meados do séc. XVIII e se desenvolveu até 1960 (MENDES, 1998).

A pedreira é limitada pela própria serra a Noroeste, Nordeste e Sudeste, originando paredes rochosas com valores de inclinação de aproximadamente $30^{\circ}$. O sector NE apresenta uma vertente sub-vertical, aproximadamente com $100 \mathrm{~m}$ de altura, bordejada pela estrada 109-B. O sector NW é particularmente propício à ocorrência de movimentos em massa, uma vez que a vertente foi explorada segundo os planos de estratificação, com pendores de cerca de $30^{\circ}$.

Nesta pedreira, as condições gerais de instabilidade das vertentes concorrem para a implantação de taludes de aterro com vista à alteração da geometria das vertentes e à criação de taludes de estabilização. Uma vez criados os diversos degraus, a fase posterior deverá contemplar a introdução de solo e de coberto vegetal, com o objectivo de diminuir o impacte visual e de criar condições de bioestabilização.

A Pedreira Sul e os edifícios adjacentes permitem perspectivar um conjunto de equipamentos fundamentais para a valorização do Monumento Natural do Cabo Mondego, e que incluem espaços museológicos e de acolhimento de visitantes (fig. 5).

\subsubsection{Os espaços de Ciência Viva e museológicos}

Para este sector é proposta a implantação de um espaço de Ciência Viva que, através de módulos que incluam reconstituições de paleoambientes, possibilite aos visitantes reconhecer as condições de vida dos diversos elementos florísticos e faunísticos que povoaram o Cabo Mondego ao longo do tempo geológico. No entanto, o espaço de Ciência Viva terá, também, lugar num dos edifícios existentes, no sentido de permitir realizar actividades complementares ao espaço exterior.

Os diversos edifícios actuais da fábrica, os anexos de pedreira e os equipamentos fixos e móveis, depois de sujeitos a obras de manutenção, podem albergar espaços museológicos vocacionados para diferentes temáticas no âmbito da arqueologia industrial.

As instalações da fábrica são testemunhos de actividade mineira secular e podem ser utilizadas e incorporadas num pólo dedicado a arqueologia industrial e mineira, considerando que um "Museu Arqueológico Industrial é, por vocação, a melhor forma de ilustrar o desenvolvimento e a evolução das técnicas industriais das Comunidades" (PINTO, 2006, pág. 119).
Os vestígios das estruturas mineiras da antiga mina (casa de escolha de carvão, oficinas, entradas de galerias, poços verticais e chaminés de ventilação) são complementos valiosos do espaço museológico. Assim, a temática da museologia industrial não estará apenas confinada a espaços fechados (salas), uma vez que, no seu conjunto, as instalações representam episódios da história das indústrias que se desenvolveram em diferentes locais do Cabo Mondego.

O sector museológico deverá contemplar uma área dedicada ao Património Natural, com o objectivo de possibilitar um acesso mais fácil e sumário aos diversos aspectos que são visualizados durante uma visita ao Cabo Mondego. Este espaço, vocacionado para a educação em geociências, poderá albergar um auditório, uma biblioteca e um centro de interpretação, com o objectivo de apoiar actividades científicas.

\subsubsection{A Pousada da Juventude}

A revitalização deste espaço passa também pela criação de possibilidades de alojamento, em pleno Cabo Mondego, para todos aqueles que desejem explorar a serra e o mar, bem como toda a geodiversidade ali existente. A implantação de uma Pousada da Juventude, inserida num dos edifícios existentes, corresponde a uma solução que concorre para a melhoria da oferta hoteleira, visando um público mais jovem, durante todo o ano, e não apenas durante a época balnear e períodos de férias escolares.

\subsubsection{Outros serviços}

Tendo em consideração os espaços propostos, afigura-se essencial a criação de serviços de restauração, com o objectivo de proporcionar maior diversificação na oferta e de cativar o público. Num dos edifícios da fábrica, poderá ser implantado um espaço de restauração, que pode ser complementado com locais de diversão nocturna.

\subsection{A Pedreira Centro}

As acções a desenvolver nesta pedreira estão condicionadas pela presença de um aterro sanitário de resíduos sólidos urbanos que, em 1986, foi sujeito a encerramento controlado.

Esta pedreira é limitada, a Norte e a Este, por paredes rochosas praticamente verticais (fig. 6). Assim, torna-

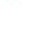



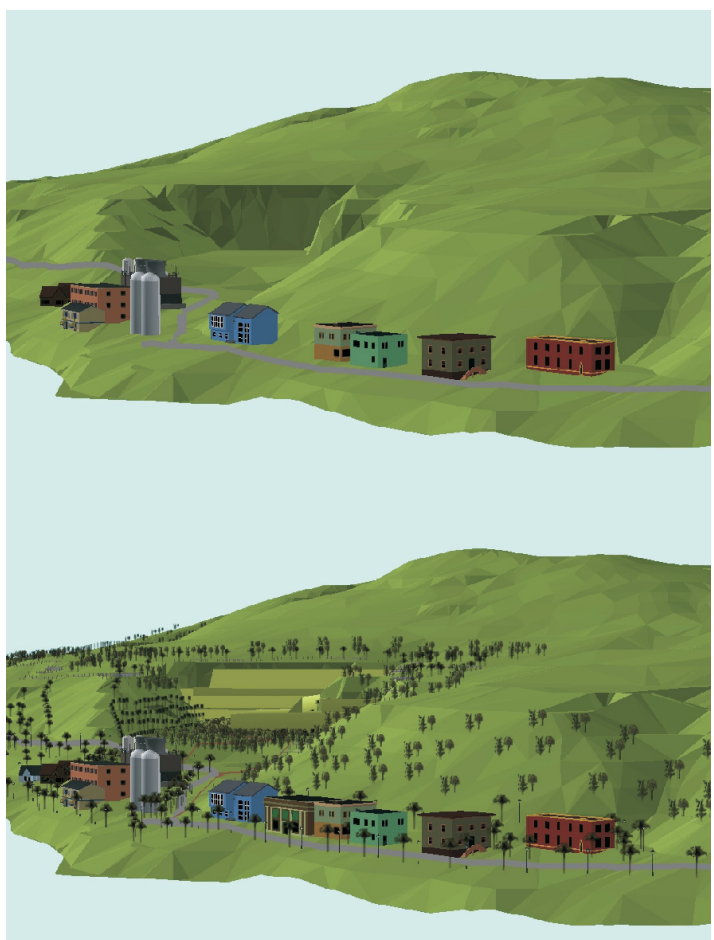

Fig. 5. Representação da Pedreira Sul e edifícios adjacentes, incluindo os equipamentos relativos a espaços museológicos e a acolhimento de visitantes.

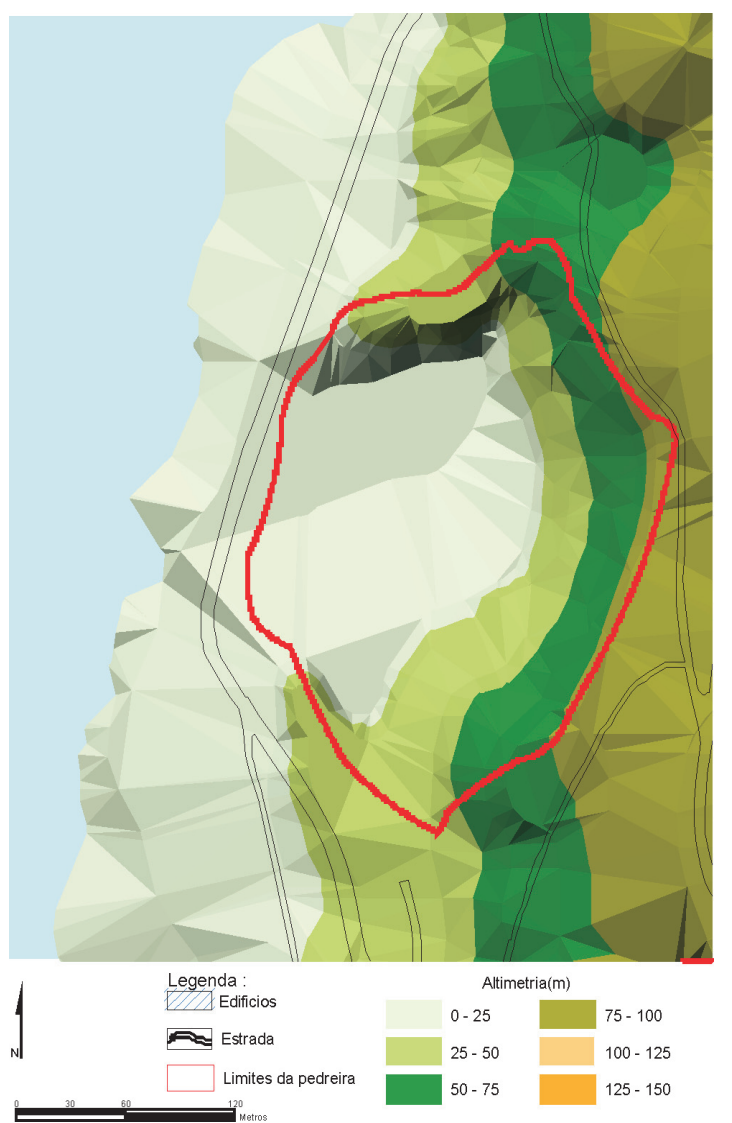

Fig. 6. Delimitação da Pedreira Centro. se imperativo que sejam criadas condições de estabilização dos taludes, com a introdução de patamares por aterro, com o objectivo de minimizar - impacto visual desta pedreira e reduzir drasticamente os riscos de desabamento.

A instalação dos referidos patamares deve ser executada tendo em consideração a possibilidade de observação, na vertente Este, de uma lacuna estratigráfica entre os andares Caloviano e Oxfordiano, que representa um local de grande interesse geológico e de elevado valor científico/didáctico.

$\mathrm{Na}$ área ocupada pelos patamares perspectiva-se a criação de um espaço de lazer, com um parque de merendas, que permita apoiar o desenvolvimento de actividade ao ar livre. A ligação entre os patamares permite que se possa estabelecer ligação entre o sector superior da pedreira (na vertente Este), limitado parcialmente por uma estrada, e a base da pedreira, mais próxima do mar.

A base da pedreira estende-se por uma área aplanada, na qual poderão ser implantados dois edifícios, destinados a albergar espaços de restauração e de diversão nocturna, os quais são complementados com a instalação de um parque de estacionamento, tendo em consideração a integração paisagística dos mesmos (fig. 7).
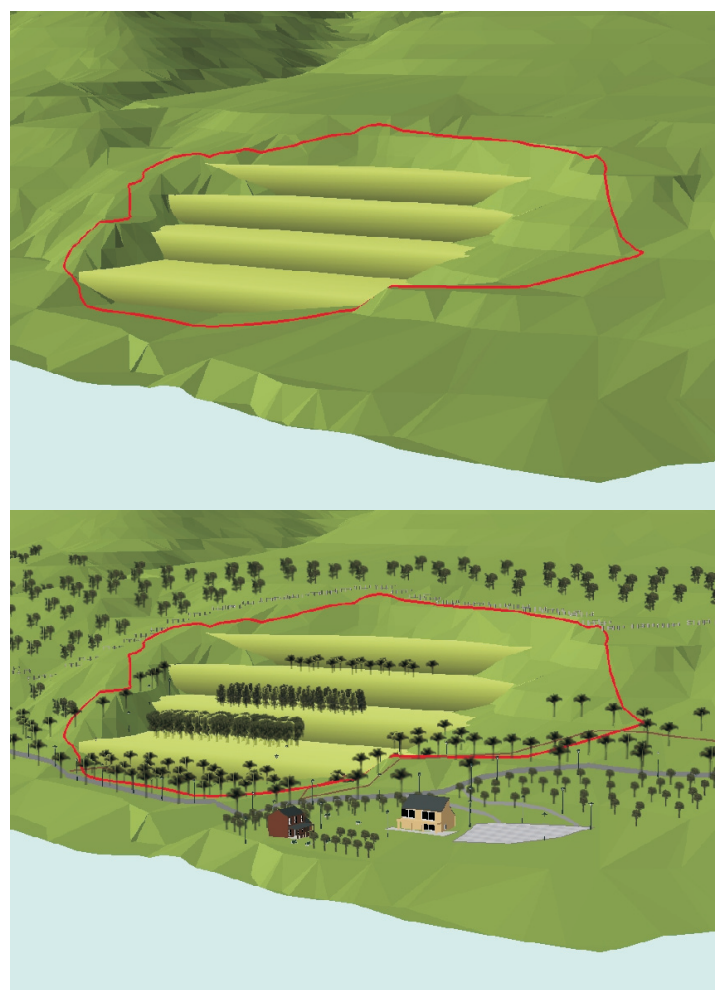

Fig. 7. Representação das fases de evolução das obras de recuperação da Pedreira Centro. 


\section{A Pedreira Norte}

No conjunto das pedreiras consideradas, a Pedreira Norte (fig. 8) é aquela que engloba mais dificuldades na concepção de uma reconversão paisagística e, também, a que se configura mais difícil de ser revitalizada com funções que possam constituir uma mais-valia.

Com a delimitação da área do Monumento Natural, parte da área de extracção do sector Norte desta pedreira (actualmente em fase de exploração), ficou afecta a essa figura jurídica. Esta situação contribuiu para a não destruição dos testemunhos da morfologia original do terreno e das arribas, passíveis de serem observados no Vale da Anta.

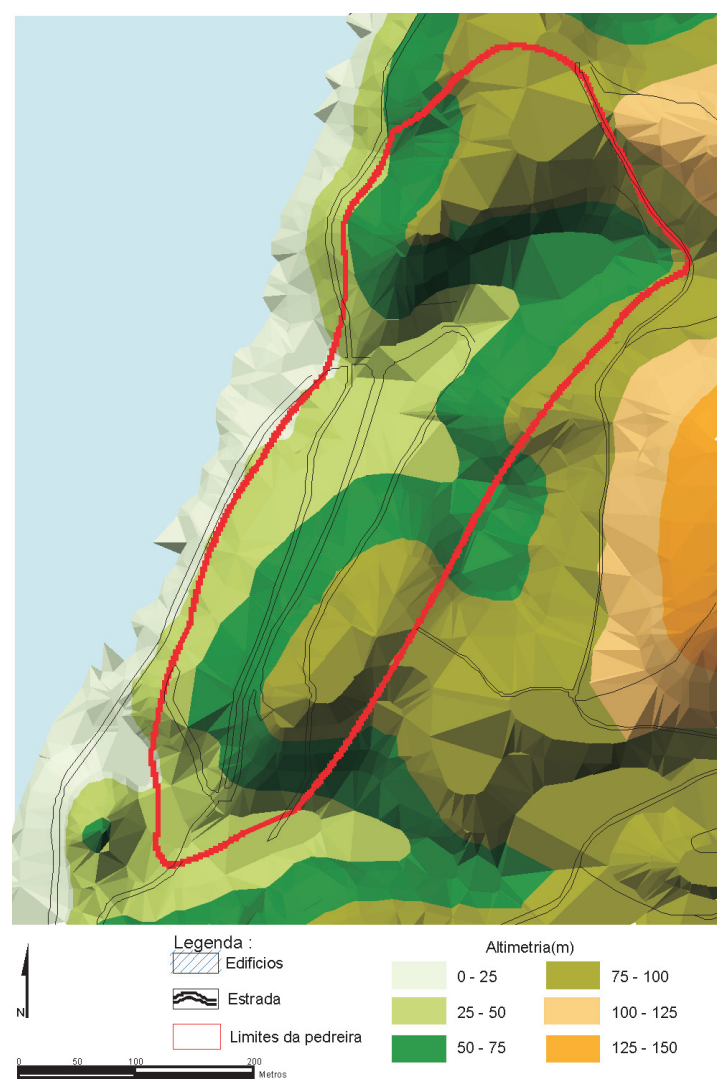

Fig. 8. Delimitação da Pedreira Norte.

Durante a fase de exploração desta pedreira foram, sucessivamente, criados taludes que diminuem a probabilidade de ocorrência de movimentos em massa, contribuindo para situações de maior estabilidade nas vertentes.

A criação de taludes, como foi proposta para as pedreiras a Sul, implicaria a movimentação de elevadas volumetrias de materiais para aterro. Assim, no sentido de reduzir a quantidade de materiais sujeitos a movimentações, propõe-se que o abandono desta actividade seja controlado, visando a progressiva configuração dos taludes em função da estabilização dos terrenos e da introdução de coberto vegetal.

A extensa área que caracteriza esta pedreira pode albergar diferentes espaços, que podem ser conjugados no sentido de minimizar os diversos impactes visuais e estéticos que se manifestam por uma extensão de praticamente $1000 \mathrm{~m}$ (N-S), entre as arribas e as vertentes, ocupando, no seu total, uma área aproximada de 10 hectares (fig. 8).

Para esta área de pedreira é ponderada a criação de um lago, entendido aqui no conceito de piscina biológica, onde se produz um ecossistema aquático auto-suficiente, capaz de manter as características bio-físico-químicas da água, através da introdução de fito e zooplâncton (figs. 9 e 10).

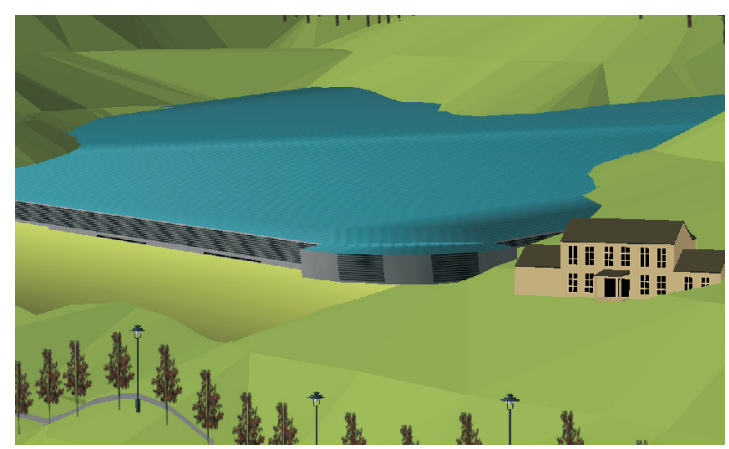

Fig. 9. Representação do lago a instalar na Pedreira Norte.

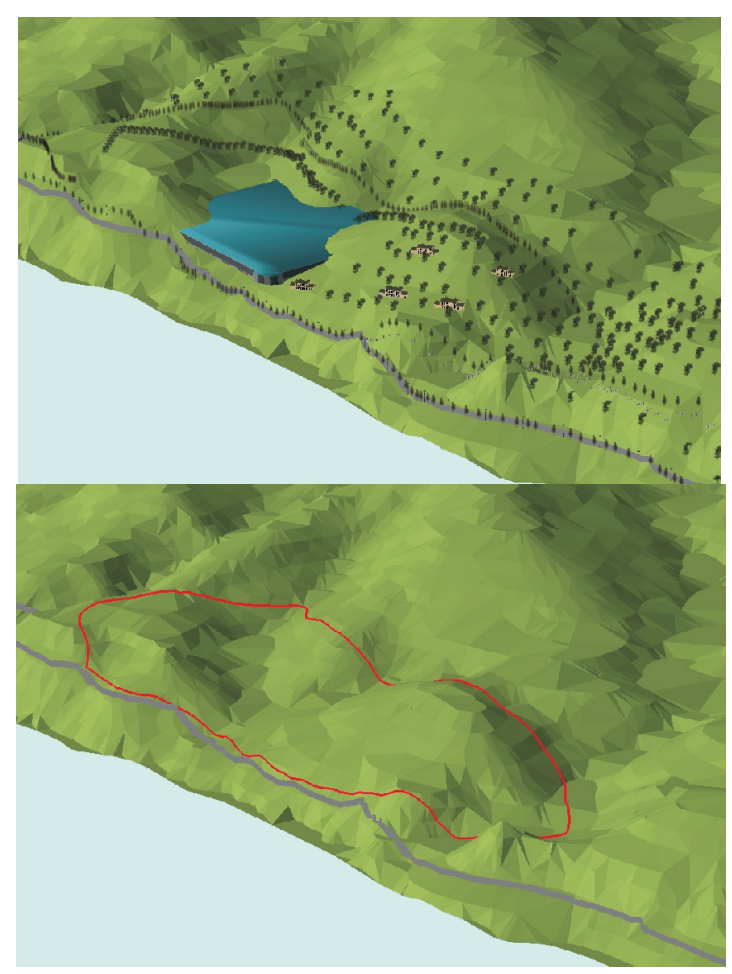

Fig. 10. Representação das fases de evolução das obras de recuperação da Pedreira Norte. 
A criação de ecossistemas aquáticos em pedreiras, sob a forma de lagos, demonstra ser uma prática corrente em muitos projectos de reabilitação de áreas degradadas, uma vez que os custos inerentes são relativamente reduzidos. Por outro lado, o efeito estético concorre para a diminuição dos impactes visuais, pela recriação de condições necessárias ao desenvolvimento de espécies, pelas actividades de lazer que permitem desenvolver, entre outros aspectos positivos que the estão associados.

A extensa área que constitui esta pedreira possibilita, ainda, que possa ser projectado um outro espaço com uma função de lazer. Assim, é proposta a criação de um cinema ao ar livre - Drive-In -, conceito pouco implementado no nosso país, o qual permite que as pessoas possam assistir a uma projecção cinematográfica, a partir das suas viaturas. A instalação e localização deste equipamento devem ter em consideração a dinâmica dos vários factores atmosféricos que afectam esta área, em particular o regime dos ventos e a existência de nevoeiros.

\section{A actividade turística}

O Geoturismo, actividade turística ligada essencialmente ao Património Natural de uma região, é uma forma de promover e de desenvolver o Cabo Mondego, de forma equilibrada, permitindo a sua valorização ao nível ambiental e paisagístico, e possibilitando o contacto com a Natureza de forma lúdica e até mesmo pedagógica (BRILHA, 2008).

No caso da Figueira da Foz, cidade próxima do Cabo Mondego, as actividades turísticas correntes estão associadas ao fluxo de pessoas durante a época estival, o que confere uma marcada sazonalidade na procura, acompanhada de uma massificação de turistas. A área do Cabo Mondego apresenta características bem distintas, e a sua utilização, com fins turísticos, obriga a um planeamento de actividades distribuídas ao longo do ano, diversificando as ofertas e fazendo uso de um recurso turístico cada vez mais procurado, e cujos destinos se intersectam com o Património Natural. A concepção e implementação de percursos no Cabo Mondego constituem uma estratégia de valorização incontornável do seu potencial geoturístico.

\section{Aspectos conclusivos}

Em 1991, Portugal foi um dos 30 países que ratificou a Declaração Internacional dos Direitos à Memória da
Terra, que visa a protecção do património geológico, através de todas as necessárias medidas legais, financeiras e organizacionais (RAMALHO, 1991). O Cabo Mondego foi objecto de protecção legal em 1998, estando actualmente classificado como Monumento Natural, mas carece de um plano estratégico que garanta a sua conservação e valorização.

Uma das formas de preservar, conservar e divulgar a geodiversidade deverá passar pela concepção de um plano de conservação e valorização que contemple a existência de novas funções e atracções neste espaço, cativando a atenção do público em geral, e incrementar, progressivamente, as ideias decorrentes da importância do Património Natural (encarado na sua vertente geológica), da sua conservação e protecção. Esta situação poderá contribuir para o incremento de uma cultura de turismo baseado em valores naturais - o turismo de natureza e - Geoturismo. Um número crescente de pessoas, nas proximidades das escarpas das pedreiras abandonadas, aumentaria os riscos de movimentação em massa pelo incremento da vulnerabilidade. Daí que a redução destes riscos tenha que ser considerada sempre em primeiro lugar.

A importância do Cabo Mondego nas suas diferentes vertentes é, talvez, o argumento mais válido para traçar estratégias para a recuperação ambiental das pedreiras, com objectivos intrínsecos à geoconservação e valorização. No entanto, a revitalização funcional assume, claramente, uma posição de destaque, inerente à criação de um novo espaço atractivo e dinâmico, capaz de gerar novos fluxos de pessoas, de capitais e de conhecimentos, e possibilitando, numa perspectiva de desenvolvimento sustentável, uma melhoria das condições de vida das populações.

As propostas contidas no presente projecto permitem estabelecer um conjunto de cenários de recuperação do Cabo Mondego, região fortemente marcada pelos efeitos decorrentes da actividade industrial extractiva, designadamente de calcário, que representam uma enorme volumetria de materiais explorados.

Torna-se imperativo que se definam estratégias de recuperação ambiental de todo este espaço tendo em consideração a existência de diversos valores patrimoniais, os quais podem estar na base da sua revalorização.

Não se propõe, aqui, apenas a diminuição dos impactes visuais e dos riscos que existem neste espaço, mas sim a sua revitalização funcional, biológica, económica e cénica, conferindo-lhe novas dinâmicas e funções, apoiadas em políticas de 
desenvolvimento sustentável e de ordenamento do território. É um processo cujas acções são destinadas a evitar e compensar a degradação ambiental, visando a valorização da geodiversidade, da paisagem e do património natural e industrial.

Apesar da sua beleza e importância, o Cabo Mondego encontra-se um pouco marginalizado e numa situação de periferia face às actividades turísticas que se desenvolvem no contexto da área de influência da Figueira da Foz, enquanto região turística. A proposta de criação de espaços e serviços diversos, com funções distintas, permite fundamentar a tese de que o Cabo Mondego pode ser considerado como um novo pólo de desenvolvimento para o Município e territórios envolventes.

\section{Referências Bibliográficas}

ANDRADE, J.B. (2004) - "Los braquiópodos del tránsito Jurásico Inferior-Jurásico Medio de la Cuenca Lusitánica (Portugal)". Colóquios de Paleontologia, 56: 5-196.

BRILHA, J. (2008) - Geodiversidade - valores e usos. UM, Braga, pp. 15

BriLHA, J. (2005) - Património geológico e geoconservação: a conservação da natureza na sua vertente geológica. Viseu, Palimage Editores, 190p.

Brilha, J.; Andrade, C.; Azerêdo, A.; Barriga, F. J. A. S.; Cachão, M.; Couto, H.; Cunha, P. P.; Crispim, J. A.; Dantas, P.; Duarte, L. V.; Freitas, M. C.; Granja, M. H.; Henriques, M. H.; Henriques, P.; Lopes, L.; Madeira, J.; Matos, J. M. X.; Noronha, F.; Pals, J.; PiçarRa, J.; Ramalho, M. M.; Relvas, J. M. R. S.; Ribeiro, A.; Santos , A.; Santos, V.; Terrinha, P. (2005) - "Definition of the Portuguese frameworks with international relevance as an input for the European geological heritage characterisation". Episodes. Vol. 28, No 3, 177-186.

Henriques, Maria Helena (1994) - The AalenianBajocian boundary at Cabo Mondego (Portugal). Miscellanea. Roma, Ser. Geol. Naz. 5, p.63-77.

Henriques, Maria Helena (1998) - O GSSP (Global Stratotype Section and Point) do Bajociano (Cabo Mondego, Portugall. Livro guia das excursões do $\checkmark$ Congresso Nacional de Geologia. Lisboa, IGM, p. 59-63.

Henriques, Maria Helena (1988) - "O Jurássico do Cabo Mondego e a Projecção Internacional do Património Geológico Português". I Encontro
Internacional sobre Paleobiologia dos Dinossáurios, Lisboa, Resumos, Lisboa, 1998, p. 98-103.

GonçAlves, F.(1959) - "Lepidotus do Jurássico do Cabo Mondego". Bol. Mus. Lab. Min. Geol. Da Fac. C. da Univ. Lisboa. Lisboa. Vol 8, Fasc. 1 (1959), p 3-5

Lapparent, A. (1951) - "Empreintes de pás de Dinosauriens dansle Jurassique de Cap Mondego (Portugal)". C. R. Somm. S. G. France. Paris. 14 (1951), 251

Mendes, José M. Amado (1998) - "Cabo Mondego (Figueira da Foz): exploração mineira e indústria". Sep. de Arqueologia Industrial.1998. 3a Série, vol. 2, no 1-2.

Mouterde, R. et al. (1978) - "Stratigraphie et faune du Lias et de la base du Dogger au Nord du Mondego, Quiaios et Brenha". Comunicações dos Serviços Geológicos de Portugal, Tomo LXIII, p. 83-104.

Oliveira, S.; Henriques, M. H. P. (2000) - O Património Geológico Português e a sua Integração nas Áreas Protegidas do Território Nacional. Livro de resu-mos do I Congresso Ibérico de Paleontologia - XVI Jornadas de la Sociedad Española de Paleontologia. Évora: Universidade de Évora.

PaVIA, G.; EnAY, R. (1997) - "Definition of the AalenianBajocian Stage boundary". Episodes, Vol. 20, № 1, p. 16-22

Pinto, Soares J. (1997). - Contributo para a Recuperação Ambiental das Pedreiras Norte e Sul do Cabo Mondego. Dissertação de Mestrado, Universidade de Coimbra.

Ramalho, M. M. trad. (1991) - "Declaração Internacional dos Direitos à Memória da Terra (Digne, 1991)", Comun. Serv. Geol. Portugal, t. 77, pp. 147-148

Santos, J. M. - "Complexo Industrial do Cabo Mondego: Sua origem e Evolução Através dos Tempos". Cadernos Municipais da Câmara Municipal da Figueira da Foz, 10 (1982), 109 p.

Solla, Luiz de Castro e (1970) - "Primeiros tempos da Mina do Cabo Mondego". Boletim de Minas, Lisboa, vol 7, nำ1, p 5-47.

Vianna, A. (1949) - "Um Peixe do Lusitano do Cabo Mondego". Com. Serv. Geol. Portugal, Lisboa, T. XXX.

\section{Agradecimentos}

À Prof. Maria Helena Henriques (DCT- FTUC), pelo incentivo amigo. Bem-haja. 